(c) American Dairy Science Association, 2003.

\title{
Identification and Characterization of Location Decision Factors for Relocating Dairy Farms ${ }^{1}$
}

\author{
J. E. Winkler Stirm ${ }^{2}$ and N. R. St-Pierre \\ Department of Animal Sciences, The Ohio State University, Columbus 43210
}

\begin{abstract}
A survey was conducted to determine the importance of various location factors during the site selection process for relocating dairy farms. The objectives were to identify the importance of location decision factors (LDF) and characterize how importance differs among respondents with different demographic characteristics. Information was collected from sampled populations of Grade A milk producers in the top 35 milkproducing states in the United States and from U.S. agribusiness professionals using a mailed questionnaire. Location decision factors $(n=110)$ were rated on importance using a numerical scale of 0 to 10 , where 0 $=$ not important and $10=$ critically important. Demographic data were collected from each respondent. Of 906 respondents, $72.4 \%$ identified their primary occupation as dairy producer. The five overall most important LDF were 1) availability of fresh water supplies $(9.16 \pm 0.05) ; 2)$ availability of land for waste management $(8.94 \pm 0.05)$; 3) average mailbox price of milk $(8.79 \pm 0.05) ; 4)$ quality of fresh water supply $(8.41 \pm$ 0.06 ); and 5) complexity of laws governing waste management $(8.35 \pm 0.06)$. Factors pertaining to dairy production activities, such as cost of feeds and milk handling, were prevalent among those LDF in the upper quartile of importance. Region and herd size had significant effects on the overall importance of LDF. The relative importance of factors differed between western and eastern regions of the United States. Observed differences in importance of LDF among subclasses of respondents suggest that characteristics of the geographic regions evaluated and dairy production activities at various scales affect perceived importance of certain LDF.
\end{abstract}

(Key words: farm location, relocation, survey)

Received March 3, 2003.

Accepted June 4, 2003.

Corresponding author: N. R. St-Pierre; e-mail: st-pierre.8@ osu.edu.

${ }^{1}$ Salaries and research support were provided by state and federal funds appropriated to the Ohio Agricultural Research and Development Center, The Ohio State University. Manuscript No. 7-03AS.

${ }^{2}$ Current address: USDA Farm Service Agency, 200 N. High St. Columbus, $\mathrm{OH} 43215$.
Abbreviation key: $\mathbf{C}=$ Central; $\mathbf{L D F}=$ location decision factors; $\mathbf{M W}=$ Midwest; $\mathbf{N E}=$ Northeast; $\mathbf{N W}=$ Northwest; $\mathbf{S E}=$ Southeast; $\mathbf{S W}=$ Southwest.

\section{INTRODUCTION}

Much research concerning the location decision process has been published (McPherson, 1995; Karakaya and Canel, 1998; Hack, 1999). The majority of this research, however, has focused on the location decision process of large-scale, nonagricultural industries. Similarities between modern animal agriculture and nonagricultural industries suggest that the location decision process for dairy farms seeking to relocate or expand may be expected to parallel the process used by largescale, nonagricultural segments of industry.

\section{The Location Decision}

The choice of a new location is critical to a business's survival as it has strategic implications, often involving the irreversible, long-term commitment of resources. Location can directly impact the profitability of a business since costs, including labor, transportation and other fixed and variable costs, and market prices received may vary considerably among geographic locations. Location may determine if businesses requiring unique inputs or specific market access are able to satisfy those needs. The consequences of location reach beyond traditional business considerations since attributes of a community may affect the ability of the business to retain or recruit labor and impact the satisfaction of the manager and their family.

\section{Location Decision Factors}

The choice of a location involves the evaluation of location decision factors (LDF) relative to the location. The list of LDF can be very large and may include aspects of market access, raw material requirements, input and product transportation, labor requirements, climate, governmental regulations, utilities access, and community attributes. Schmenner (1982) suggested that individual firms must differentiate between "musts" and "wants" to initiate a successful location 
search. "Musts" are LDF considered critical to the firm. "Wants" are noncritical LDF that can be traded off to compensate for "musts." As a result, a hierarchy of importance of LDF is established.

Many elements influence the importance of LDF. Firms seeking to relocate are likely to consider LDF related to the motivations underlying the decision to relocate to be highly important (Browning, 1980; Schmenner, 1982; Cohen Mason, 1996). For example, relocation may be a means of satisfying strategic goals, such as increasing profitability through increased cost effectiveness. Such firms are likely to consider LDF related to cost factors, including labor, input, or transportation costs, to be the most important.

Industrial characteristics may influence the importance of LDF. The degree to which LDF are considered critical to the business varies greatly among industrial segments according to production activities, input requirements, and marketing and managerial preferences unique to those industries (Browning, 1980; Schmenner, 1982; Chapman and Walker, 1991). For example, service-oriented industries, such as health care providers and consultants, rely on the distribution of services directly to consumers and therefore place high importance on LDF related to market accessibility.

Personal characteristics of the decision maker may also influence the importance of LDF. Demographic characteristics, such as age, gender, and marital and family status, may influence an individual's desire to relocate (Gould and Penley, 1985; Stroh, 1999; Eby and Russell, 2000). Considering the relationship between a firm's motivation to relocate and the importance of LDF, it is reasonable to expect that personal characteristics that influence an individual's willingness to relocate will also influence the importance of certain LDF in the decision process.

The importance of LDF among agricultural livestockproducing industries has not been adequately researched. The limited literature available, however, suggests that the importance of LDF is influenced by many of the same elements observed among nonagricultural industries. Abdalla et al. (1995) and Sullivan et al. (2000) indicated that changes in the location of agricultural operations are direct consequences of environmental regulation enforcement and the status of rural population growth. Market access (Butler and Ekboir, 1997; Barrett, 1998; Mooney, 2000) and LDF related to natural resource requirements and raw material inputs are consistently characterized as being important (Barrett, 1998; Smith et al., 1999; Mooney, 2000). Barrett (1998) reported that the ability to handle wastes is a primary concern when selecting a location; however, presence of a dairy infrastructure was minimally important. Quality of life considerations are also presented as LDF worthy of significant evaluation in popular press (Dairy Herd Management Staff, 2000; Mooney, 2000).

The purpose of this research was to evaluate the importance of $\mathrm{LDF}$ in the location decision of relocating dairy farms. Overall objectives were to identify the most important LDF and characterize how importance differs among respondents across geographic regions and herd sizes. The research hypotheses were: 1) LDF directly related to daily dairy production activities are most important to the location decision for relocating dairy farms; and 2) the importance of LDF vary among geographic regions and herd sizes.

\section{MATERIALS AND METHODS}

\section{Instrument Development}

Location decision factors were identified using information gathered from reviewed literature and discussions with dairy industry specialists. Content validity of the survey instrument was established by face-toface interviews of a pilot test group and critiques by dairy industry professionals. Questionnaires were distributed to two pilot test populations: students enrolled in an advanced dairy management course at The Ohio State University and attendees of a dairy case study presentation at the 2000 ADSA annual meeting. Internal reliability was established based on calculations of Pearson correlation coefficients and Cronbach's alpha reliability tests (Oppenheim, 1992).

The final survey instrument was a mailed questionnaire. The questionnaire presented respondents with $\mathrm{LDF}(\mathrm{n}=110)$ related to waste handling, climate, land characteristics, market characteristics, labor considerations, farm inputs, dairy infrastructure, business climate, regulatory environment, community characteristics, and personal factors. Respondents were instructed to rate each LDF as to its importance when selecting a site for relocating their own dairy farm or an advisee's dairy farm using an 11-point numerical scale of importance that ranged from 0 to 10 . Zero represented "unimportant," 5 represented "somewhat important," and 10 represented "critically important." The survey instrument also collected respondent demographic information, including primary job activity, age, gender, state, and county of current residence, level of education, marital status, family status, history of farm relocation involvement, and milking cow herd size.

\section{Sampling Methods}

Two target populations were identified: dairy producers and agribusiness professionals active within the dairy industry. The sampling frame for the population 


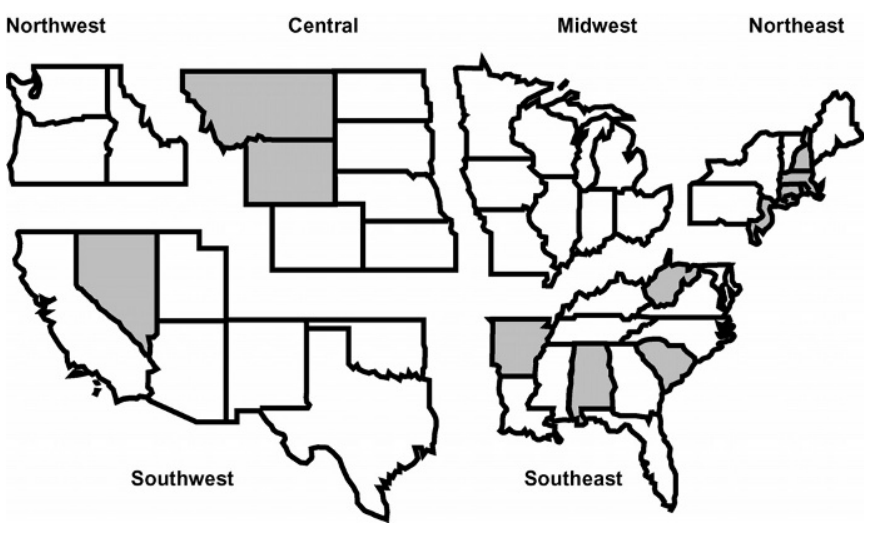

Figure 1. Regions established for stratification of the population of dairy producers. States that were surveyed are shown with a white background.

of dairy producers consisted of address lists of Grade A milk producers provided by state agencies from the top 35 milk-producing states in the United States. This population was stratified according to region, with region defined as one of six geographical groupings of states with common climatic and topographical characteristics (Figure 1): Central (C), Midwest (MW), Northeast (NE), Northwest (NW), Southeast (SE), and Southwest (SW). Alaska and Hawaii were excluded. Within each stratum, counties from states in the sampling frame were weighted according to the number of herds with more than 100 milking cows, as reported in the U.S. Census of Agriculture (NASS, 1997), resulting in a planned sampling bias toward larger-than-average herds. As a result of the weighting process, counties with no or low proportions of midsize and large herds were eliminated from the sampling frame. Addresses of dairy producers were selected for the sampled population using random sampling techniques.

The sampling frame for the population of agribusiness professionals consisted of address lists of individuals obtained from professional organizations, industry events, and industry publications. Addresses of agribusiness professionals were selected using random sampling techniques.

The sample size $\left(\mathrm{n}_{0}\right)$ for each stratum of both populations was calculated using the following equation (Lohr, 1999):

$$
\mathrm{n}_{\mathrm{o}}=\left[\left(\mathrm{z}_{\alpha}^{2}\right)\left(\mathrm{S}^{2}\right)\right] / \mathrm{e}^{2}
$$

where $z_{\alpha}=2.0, S$ (standard deviation) $=2.5$, and $e$ (margin of error $)=0.5$. Sample size $\left(\mathrm{n}_{0}\right)$ calculations were adjusted for expected response rates to determine the actual sample size (Table 1).

\section{Data Collection}

Data were collected using the tailored design method for mailed questionnaires (Dillman, 2000). Each questionnaire was numerically identified to monitor response. The first mailing occurred on February 10, 2001. A cover letter and postage-paid, self-addressed return envelope were included with each questionnaire. Reply incentives were used. A reminder postcard was sent to nonrespondents $2 \mathrm{wk}$ after the initial mailing. The total response rate from the first mailing was $23.2 \%$ of sampled dairy producers and $40.1 \%$ of sampled agribusiness professionals (Table 1). The anticipated response rate (33\%) was not obtained from the dairy producer population; a second mailing was required for this population.

The second mailing of questionnaires to dairy producers occurred on March 24, 2001. Concerns of nonresponse bias resulted in the use of a new sampled population of dairy producers. The second mailing consisted of cover letters and postage-paid, self-addressed return envelopes identical to those used for the first mailing. A reply incentive was used but was not identical to the first mailing. Reminder postcards were mailed to nonrespondents 2 wk following the initial mailing. Total response rate from the second mailing was $25.0 \%$ (Table 1). Chi-squared analysis indicated there were no differences among respondents to the first and second mailings $(P=0.55)$, and the two groups were pooled into a single sample of dairy producers (Miller and Smith, 1983). Across all populations and mailings, 906 usable questionnaires were returned.

\section{Data Analyses}

Descriptive statistics and frequencies for demographic data were obtained using the MEANS and FREQ procedures of SAS (SAS Inst., Inc., Cary, NC). Multivariate analyses (SAS Inst., Inc.) of all LDF taken jointly were first conducted to determine the overall effects of region, herd size, relocation involvement, primary job activity, age, gender, marital status, family status, level of education, and all two-way interactions. Results showed significant differences across regions and herd sizes $(P<0.05)$. With the exception of relocation involvement, all other main effects were also significant $(P<0.05)$. Principal component analyses yielded uninterpretable vectors. Thus, data for each LDF were analyzed separately (univariate analysis) using the PROC GLM procedure of SAS (Berk, 1983). The model used included the following main effects and their two-way interactions (number of levels for each variable; Table 2): region (6), job (2), gender (2), age class (3), level of education (3), marital status (2), family status (2), prior relocation involvement (2), and herd 
Table 1. Questionnaire response rates across sampled populations.

\begin{tabular}{|c|c|c|c|c|}
\hline \multirow[b]{2}{*}{ Sampled populations } & \multirow[b]{2}{*}{$\begin{array}{l}\text { Total number of } \\
\text { questionnaires mailed }\end{array}$} & \multicolumn{3}{|c|}{ Response rate (\% of total mailed) } \\
\hline & & Initial & $\begin{array}{l}\text { After } \\
\text { postcard }\end{array}$ & Overall \\
\hline \multicolumn{5}{|l|}{ First mailing } \\
\hline Dairy producers & 1798 & 16.4 & 6.8 & 23.2 \\
\hline Agribusiness professionals & 659 & 28.8 & 11.2 & 40.1 \\
\hline \multicolumn{5}{|l|}{ Second mailing } \\
\hline Dairy producers & 1184 & 18.7 & 6.3 & 25.0 \\
\hline Agribusiness professionals ${ }^{1}$ & $\ldots$ & $\ldots$ & $\ldots$ & \\
\hline Overall response rate (unadjusted) & & & & 26.6 \\
\hline Overall response rate (adjusted) ${ }^{2}$ & & & & 24.9 \\
\hline
\end{tabular}

Table 2. Model and associated degrees of freedom.

\begin{tabular}{lc}
\hline & \\
Model source & Degrees \\
of freedom \\
\hline Region & 5 \\
Job & 1 \\
Gender & 1 \\
Age & 2 \\
Education & 2 \\
Marital Status & 1 \\
Family Status & 1 \\
Relocation Involvement & 1 \\
Herdsize & 3 \\
Total df main effects & 17 \\
Region $\times$ job & 5 \\
Region $\times$ gender & 5 \\
Region $\times$ age & 10 \\
Region $\times$ education & 10 \\
Region $\times$ marital status & 5 \\
Region $\times$ family status & 5 \\
Region $\times$ relocation involvement & 5 \\
Region $\times$ herdsize & 15 \\
Job $\times$ gender & 1 \\
Job $\times$ age & 2 \\
Job $\times$ education & 2 \\
Job $\times$ marital status & 1 \\
Job $\times$ family status & 1 \\
Job $\times$ relocation involvement & 1 \\
Gender $\times$ age & 3 \\
Gender $\times$ education & 38 \\
Gender $\times$ marital status & 905 \\
Gender $\times$ family status & 2 \\
Gender $\times$ relocation involvement & 2 \\
Gender $\times$ herdsize & 1 \\
Age $\times$ marital status & 1 \\
Age $\times$ family status & 1 \\
Age $\times$ herdsize & 3 \\
Education $\times$ marital status & 2 \\
Education $\times$ family status & 2 \\
Education $\times$ relocation involvement & 6 \\
Marital status $\times$ family status & 2 \\
Marital status $\times$ relocation involvement & 2 \\
Marital status $\times$ herdsize & 2 \\
Family status $\times$ relocation involvement & 1 \\
Family status $\times$ herdsize & 1 \\
Relocation involvement $\times$ herdsize & 3 \\
Error & 1 \\
Total df & 2 \\
\hline & \\
\hline
\end{tabular}

size class (4). Because of insufficient numbers of observations per subclass, discrete data analysis could not be used. The GLM procedure was used to solve standard linear models using unweighted least squares methods (Harvey, 1982). Consequently, resulting variance estimates and least squares means of subclasses with small numbers of observations $(\mathrm{n}<30)$ are biased. Tests of differences among least squares means, however, are robust to departures from the assumptions of normality (Harvey, 1982). Preplanned contrasts were used to evaluate: 1 ) the effect of eastern regions (MW, NE, and SE) vs. western regions (C, NW, and SW); and 2) the effect of herd size (small herds vs. midsize and large herds). Significant differences were declared at $P<0.05$. Regions and herd sizes were also compared using the 10 highest ranked LDF within each subclass. Nonparametric statistics based on ranks were considered, but none of the published methods could handle a model with the dimensions (123) and data imbalance present in our dataset.

In this paper, the discussion focuses exclusively on effects of region and herd size on the importance of LDF. Discussion of LDF is limited to those of high relative importance or of current interest to the industry. Relative importance was characterized as follows: high importance, $\geq 7.50$; moderate importance, $<7.50$ and $>5.00$; and low importance, $\leq 5.00$. These categorizations are based on approximations of the first, second, third, and fourth quartiles of overall importance, respectively.

\section{RESULTS AND DISCUSSION}

\section{Respondent Profile}

The demographic profile of questionnaire respondents $(\mathrm{n}=906)$ is presented in Table 3. Of all respondents, $72.4 \%$ identified their primary occupation as dairy producer. Across all respondents, 42 of the 48 states comprising the six regions of interest were identi- 
Table 3. Demographic profile of questionnaire respondents overall and within surveyed populations.

\begin{tabular}{|c|c|c|c|}
\hline \multirow[b]{2}{*}{ Demographic characteristic } & \multicolumn{3}{|c|}{ Percentage of respondents (\%) } \\
\hline & $\begin{array}{l}\text { All } \\
\text { respondents } \\
(\mathrm{n}=906)\end{array}$ & $\begin{array}{l}\text { Agribusiness } \\
\text { professionals } \\
(\mathrm{n}=250)\end{array}$ & $\begin{array}{l}\text { Dairy } \\
\text { producers } \\
(\mathrm{n}=656)\end{array}$ \\
\hline \multicolumn{4}{|l|}{ Region of residence } \\
\hline Central (C) & $14.4 \%$ & $4.8 \%$ & $18.0 \%$ \\
\hline Midwest (MW) & $26.8 \%$ & $50.0 \%$ & $18.0 \%$ \\
\hline Northeast (NE) & $17.8 \%$ & $17.6 \%$ & $17.8 \%$ \\
\hline Northwest (NW) & $14.7 \%$ & $7.2 \%$ & $17.5 \%$ \\
\hline Southeast (SE) & $14.1 \%$ & $10.0 \%$ & $15.7 \%$ \\
\hline Southwest (SW) & $12.3 \%$ & $10.4 \%$ & $13.0 \%$ \\
\hline \multicolumn{4}{|l|}{ Job } \\
\hline Agribusiness professionals & $27.6 \%$ & $100.0 \%$ & $0.0 \%$ \\
\hline Dairy producers & $72.4 \%$ & $0.0 \%$ & $100.0 \%$ \\
\hline \multicolumn{4}{|l|}{ Milking cow herd size ${ }^{1}$} \\
\hline No cows & $27.9 \%$ & $94.8 \%$ & $2.4 \%$ \\
\hline Small & $29.0 \%$ & $3.6 \%$ & $38.7 \%$ \\
\hline Midsize & $32.8 \%$ & $0.8 \%$ & $45.0 \%$ \\
\hline Large & $10.3 \%$ & $0.8 \%$ & $13.9 \%$ \\
\hline \multicolumn{4}{|l|}{ Relocation involvement ${ }^{2}$} \\
\hline Yes & $34.1 \%$ & $42.0 \%$ & $31.1 \%$ \\
\hline No & $65.9 \%$ & $58.0 \%$ & $68.9 \%$ \\
\hline \multicolumn{4}{|l|}{ Gender } \\
\hline Female & $8.5 \%$ & $7.6 \%$ & $8.8 \%$ \\
\hline Male & $91.5 \%$ & $92.4 \%$ & $91.2 \%$ \\
\hline \multicolumn{4}{|l|}{ Age $(\mathrm{yr})$} \\
\hline$<35$ & $11.0 \%$ & $19.6 \%$ & $7.8 \%$ \\
\hline 35 to 44 & $29.1 \%$ & $28.8 \%$ & $29.3 \%$ \\
\hline 45 to 64 & $52.3 \%$ & $48.0 \%$ & $54.0 \%$ \\
\hline$>64$ & $7.5 \%$ & $3.6 \%$ & $9.0 \%$ \\
\hline \multicolumn{4}{|l|}{ Marital status ${ }^{3}$} \\
\hline Married & $90.2 \%$ & $90.0 \%$ & $90.1 \%$ \\
\hline Unmarried & $9.8 \%$ & $9.6 \%$ & $9.9 \%$ \\
\hline \multicolumn{4}{|l|}{ Family status ${ }^{4}$} \\
\hline Children & $88.1 \%$ & $84.4 \%$ & $89.5 \%$ \\
\hline \multirow{2}{*}{\multicolumn{4}{|c|}{ Education level $^{5}$}} \\
\hline & & & \\
\hline High school & $38.4 \%$ & $10.4 \%$ & $49.1 \%$ \\
\hline Undergraduate & $46.7 \%$ & $46.0 \%$ & $47.0 \%$ \\
\hline Graduate/professional & $14.9 \%$ & $43.6 \%$ & $4.0 \%$ \\
\hline
\end{tabular}

${ }^{1}$ No cows $=0$ milking cows; Small $=<100$ milking cows; Midsize $=100$ to 499 milking cows; Large $=>499$ milking cows.

${ }^{2}$ Yes = previous involvement in relocation of one's own dairy or assisting with the relocation of a dairy farm other than one's own. No $=$ no previous involvement in relocation activities.

${ }^{3}$ Married = married or separated; Unmarried = single, divorced, or widowed.

${ }^{4}$ Children $=$ children $<18$ yr of age and children $\geq 18$ yr of age; No Children = no children.

${ }^{5}$ High School = completion of elementary or high school level education; Undergraduate = completion of undergraduate level education, including classes toward an associate's degree; Graduate/Professional = completion of graduate or professional level education.

fied as states of current residence, indicating that some of the respondents had moved outside the 35 sampled states. Samples obtained from all regions exceeded the calculated sample size $\left(n_{0}=100\right)$ necessary to obtain the desired power $(\beta<0.2$ for true differences less than 0.25 ). The level of response among the agribusiness professional population was greatest from the MW region $(P<0.001)$, indicating potential sampling or response bias within this population. No differences in the frequency of response by region $(P=0.16)$ were observed among the population of dairy producers.
Questionnaire respondents can be generally characterized as male, age 45 to 64 , married with children, college (undergraduate) educated, and not previously involved in relocation (Table 3). Over $70.0 \%$ of all respondents indicated they currently own a herd of milking cows. Among respondents with milking cows, $40.3 \%$ had herds of less than 100 milking cows (small herds), 45.5\% had herds of 100 to 499 milking cows (midsize herds), and $14.2 \%$ had herds of 500 or more milking cows (large herds). Herd size distribution of the sampled population differed considerably from U.S. herd 
size distribution reported by NASS (2001). The difference between herd size distributions of sampled and real-world populations was planned and is the result of sampling methods that incorporated intentional bias toward larger-than-average herds.

\section{Location Decision Factors}

Among all LDF evaluated, 20 were characterized as being of high relative importance (Table 4). The majority of LDF considered to be of high importance pertained to business considerations and physical requirements of the dairy operation.

Natural resources. Factors associated with the availability and characteristics of natural resources, particularly water and land, were among those LDF determined to be of high relative importance. The availability of water resources $(9.16 \pm 0.05$; Table 4$)$ was the most important LDF overall $(P<0.01)$. Importance of this LDF differed across regions $(P<0.05$; Table 5$)$. The NW region $(9.54 \pm 0.22)$ considered the availability of water to be of greater importance than the MW (8.76 $\pm 0.27)$ and $\mathrm{C}(9.04 \pm 0.24)$ regions $(P<0.10)$. An interaction between region and herd size occurred $(P<0.01$; Table 6) in which large herds within the NW region $(9.99 \pm 0.38)$ characterized the availability of water resources as being more important than did herds of comparable size within all other regions $(9.27 \pm 0.14)$.

Water quality ( $8.41 \pm 0.06$; Table 3$)$ was considered to be the fourth most important LDF overall. Relative importance of this LDF did not differ across regions or herd sizes, indicating that this LDF is consistently important within all regions and among herds of all sizes. The importance of this LDF also suggests an implication of water availability: If available water resources do not meet certain minimal quality standards, then the water supply is essentially useless.

Proximity to perennial flowing streams was determined to be of moderate importance $(7.18 \pm 0.09$; Table $3)$. Importance of this factor differed across regions $(P$ $<0.001$; Table 5) since the NW region considered this factor to be more important $(8.55 \pm 0.42)$ than did all other regions $(6.94 \pm 0.14 ; P<0.01)$. This factor may have been assessed from either an availability or waste management perspective, thus influencing overall importance.

Availability of land for both waste management (availability of land on which to incorporate animal waste $=8.94 \pm 0.05$; Table 4 ) and expansion (availability of land on which to construct and relocate $=7.88 \pm 0.06$ ) was determined to be of high importance; however, availability of land for waste management carried greater levels of importance. This would suggest that the characteristics of land impacting waste assimila- tion, such as percentage of OM $(5.93 \pm 0.08)$, would also be of high importance. Conversely, many of those corresponding LDF were rated as being only moderately important. The importance of land availability for waste management purposes differed across regions $(P$ $<0.001$; Table 5). The NW region considered the availability of land on which to incorporate animal waste to be significantly more important $(9.23 \pm 0.29)$ than did the $\mathrm{C}, \mathrm{SE}$, and $\mathrm{SW}$ regions $(8.07 \pm 0.2 ; P<0.01)$.

The extremely high importance associated with availability of water and land resources may indicate that respondents consider water and land resources to be fundamental to dairy production activities. Lack of a herd size effect on importance of these LDF suggests that water and land resources are critical elements for all sizes of dairy operations. Regional differences, however, indicate that local political and social attitudes toward use of water and land resources may impact the perceived importance of related LDF, as was illustrated within the NW region. Respondents from the NW, an environmentally sensitive area when compared to other regions, placed higher levels of importance on both of these LDF.

Waste management. LDF related to the regulation of waste management were among those determined to be of high relative importance. The complexity of state and local laws governing waste management $(8.35 \pm$ 0.06 ; Table 4) was the fifth most important LDF overall. Relative importance of this LDF did not vary across regions or herd sizes. An interaction, however, did occur between region and herd size $(P<0.05$; Table 6$)$, such that large herds within the NE region perceived this factor to be less important $(7.85 \pm 0.80)$ than herds of similar sizes in all other regions $(9.22 \pm 0.17 ; P<0.10)$.

Factors related to specific regulatory measures, including the nutrient load capacity of land (7.90 \pm 0.06 ; Table 4), were also of high relative importance, but were considered to be less important $(P<0.01)$ than complexity of regulations. This would suggest that clarity of regulations is a more significant consideration than are the number and stringency of regulations. Importance of the nutrient load capacity of land differed across regions $(P<0.001$; Table 5$)$. The NW region considered this LDF significantly more important (9.32 $\pm 0.29)$ than did all other regions $(7.86 \pm 0.12 ; P<0.01)$. Large and midsize herds perceived this LDF as being more important $(8.54 \pm 0.27)$ than did small herds $(8.10$ $\pm 0.27 ; P<0.05$; Table 7 )

Regional differences in perceived importance of waste management-related LDF suggest that local characteristics, including environmental stringency and regulatory enforcement, may influence the impact these factors have on the location decision. Variations in importance among herd sizes may reflect current policies and 
Table 4. Least squares means for importance of location decision factors (overall mean level of importance $=6.36$ ).

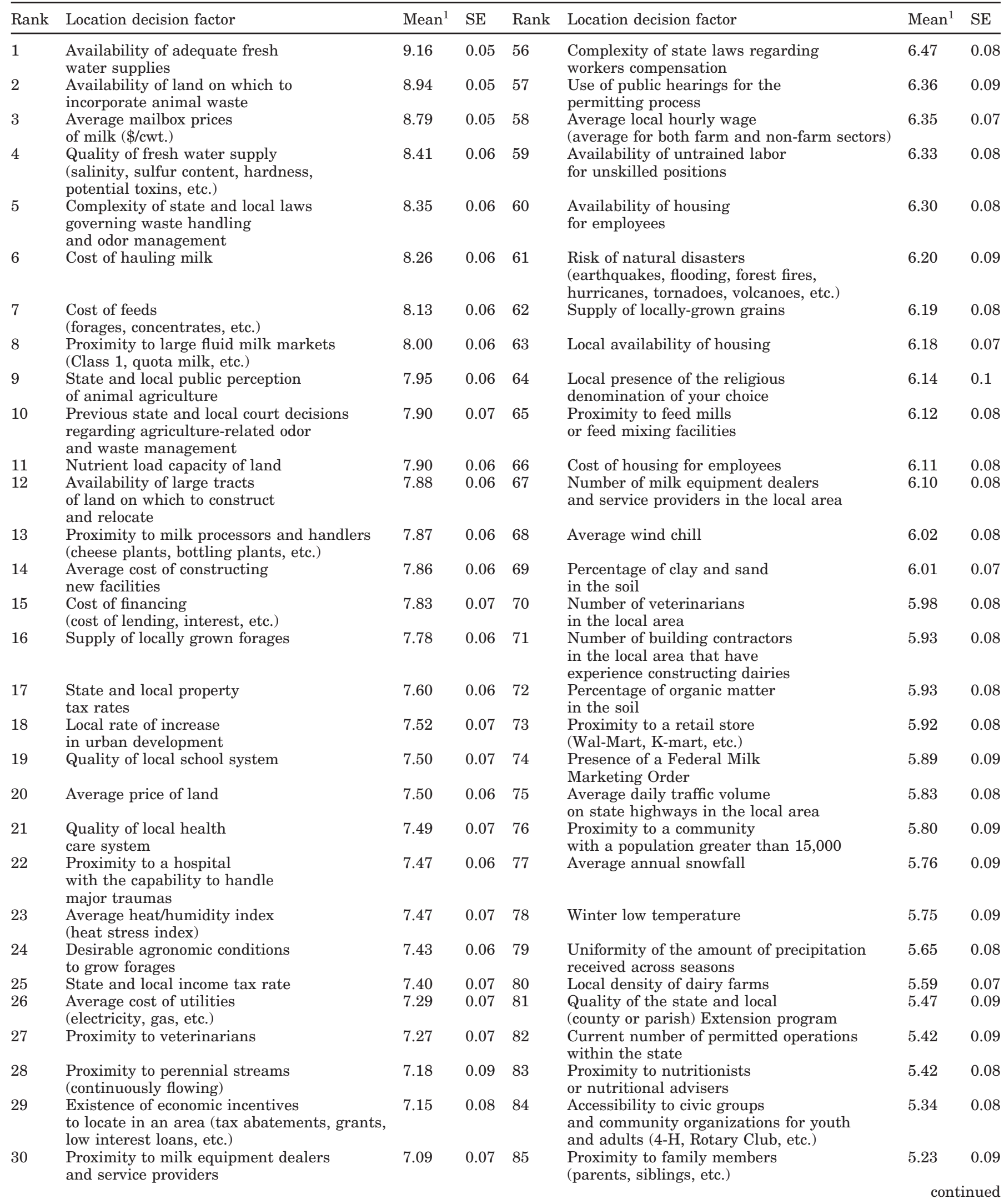


Table 4. (continued) Least squares means for importance of location decision factors (overall mean level of importance $=6.36$ ).

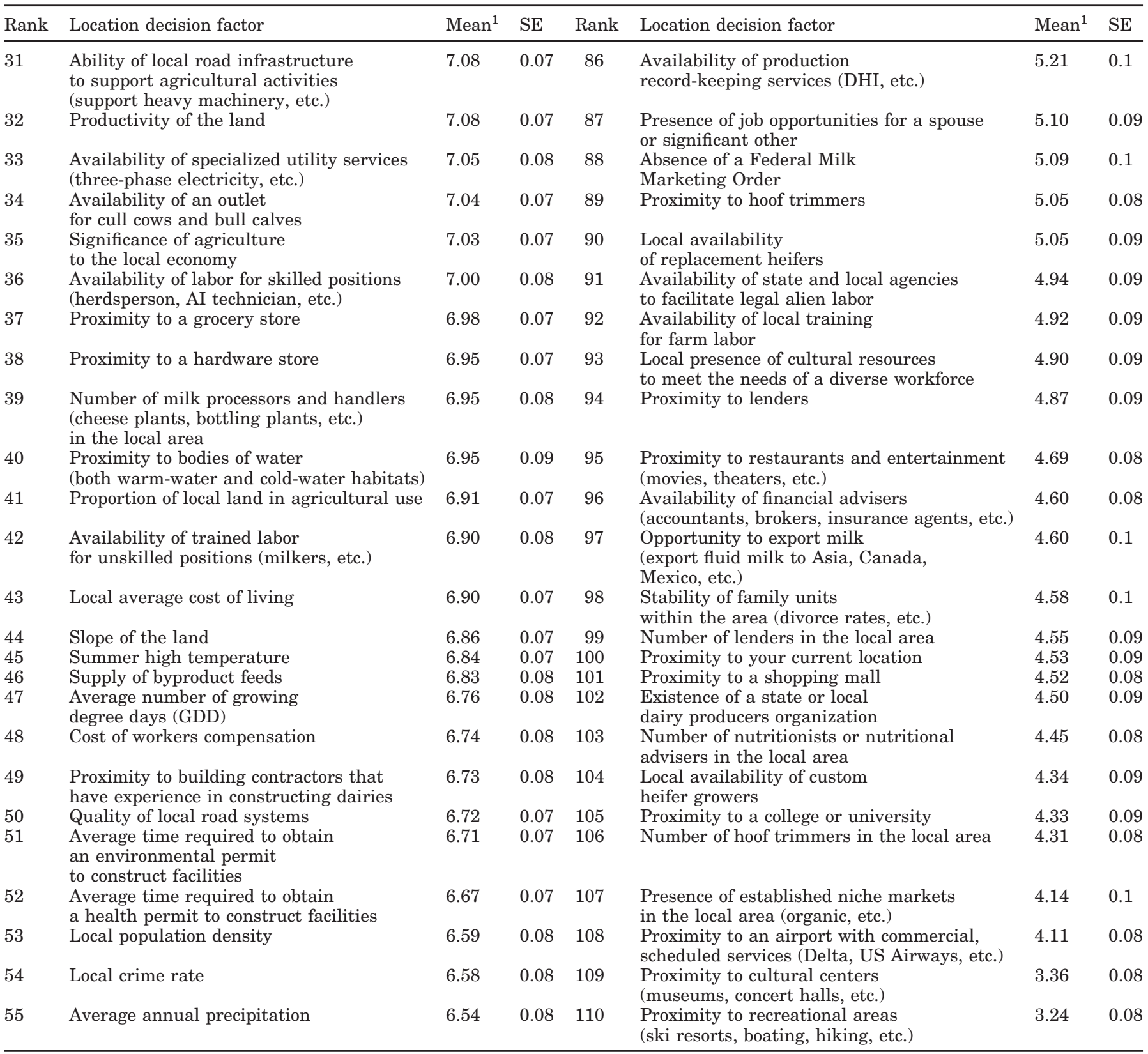

${ }^{1}$ Scale of importance: $0=$ not important; $5=$ somewhat important; and $10=$ critically important.

regulations that focus more attention on large herds than small herds. As environmental regulations and levels of compliance and enforcement become more uniform among states and herd sizes, it is anticipated that overall importance of LDF related to waste management will increase and become more consistent among regions and herd sizes.

Previous state and local court decisions regarding agriculture-related odor and waste management (7.90 \pm 0.07 ; Table 4) were also considered to be highly im- portant. Importance of this LDF varied across regions $(P<0.05$; Table 5); NE and NW regions $(8.07 \pm 0.36)$ characterized this factor as being significantly more important than did the MW region (6.36 $\pm 0.45 ; P<$ $0.01)$. An interaction between region and herd size was observed $(P<0.05$; Table 6$)$ in which large herds within the $\mathrm{C}, \mathrm{NE}$, and NW regions $(8.36 \pm 0.36)$ considered judicial attitudes pertinent to waste management issues to be more important than did large herds in all other regions $(5.70 \pm 0.37 ; P<0.01)$. These results sug- 
Table 5. Least squares means for importance of location decision factors that differed by region.

\begin{tabular}{|c|c|c|c|c|c|c|c|c|c|c|}
\hline Location decision factor & \multicolumn{6}{|c|}{ Region $^{1}$} & SE range & $\mathrm{n}$ & $P^{3}$ & $\begin{array}{l}\text { East vs } \\
\text { west } \\
P^{4}\end{array}$ \\
\hline Availability of adequate water supplies & $9.04^{\mathrm{b}}$ & $8.76^{\mathrm{b}}$ & $9.24^{\mathrm{ab}}$ & $9.54^{\mathrm{a}}$ & $9.12^{\mathrm{ab}}$ & $9.23^{\mathrm{ab}}$ & $0.24-0.27$ & 882 & $<0.05$ & NS \\
\hline to incorporate animal waste & $8.48^{\mathrm{c}}$ & $8.81^{\mathrm{cd}}$ & $9.09^{\mathrm{cd}}$ & $9.23^{\text {bd }}$ & $7.37^{\mathrm{a}}$ & $8.36^{\mathrm{ac}}$ & $0.27-0.37$ & 906 & $<0.001$ & NS \\
\hline Proximity to perennial streams & $7.47^{\mathrm{c}}$ & $7.17^{\mathrm{c}}$ & $5.21^{\mathrm{a}}$ & $8.55^{\mathrm{b}}$ & $7.33^{\mathrm{c}}$ & $6.91^{\mathrm{c}}$ & $0.42-0.47$ & 905 & $<0.001$ & $<0.01$ \\
\hline Nutrient load capacity of land & $7.60^{\mathrm{bc}}$ & $8.19^{\mathrm{b}}$ & $8.34^{\mathrm{b}}$ & $9.32^{\mathrm{a}}$ & $7.23^{\mathrm{c}}$ & $7.96^{\mathrm{bc}}$ & $0.29-0.39$ & 905 & $<0.001$ & NS \\
\hline Average mailbox price of milk ( $\$ / \mathrm{cwt}$ ) & $9.81^{\mathrm{a}}$ & $9.17^{\mathrm{ab}}$ & $8.22^{\mathrm{c}}$ & $8.50^{\mathrm{bc}}$ & $9.73^{\mathrm{a}}$ & $9.85^{\mathrm{a}}$ & $0.29-0.42$ & 892 & $<0.001$ & NS \\
\hline $\begin{array}{l}\text { Proximity to large fluid milk markets } \\
\text { Proximity to milk processors }\end{array}$ & $7.75^{\mathrm{b}}$ & $8.57^{\mathrm{ac}}$ & $8.30^{\mathrm{bc}}$ & $8.02^{\mathrm{bc}}$ & $9.19^{\mathrm{a}}$ & $8.27^{\mathrm{bc}}$ & $0.28-0.32$ & 901 & $<0.01$ & $<0.01$ \\
\hline and handlers & $8.44^{\mathrm{ad}}$ & $7.73^{\mathrm{bc}}$ & $7.96^{\mathrm{bcd}}$ & $8.88^{\mathrm{a}}$ & $7.47^{\mathrm{c}}$ & $8.36^{\mathrm{ab}}$ & $0.26-0.34$ & 901 & $<0.01$ & $<0.001$ \\
\hline $\begin{array}{l}\text { to locate in an area } \\
\text { Availability of labor }\end{array}$ & $7.32^{\mathrm{abc}}$ & $6.91^{\mathrm{ab}}$ & $7.08^{\mathrm{abc}}$ & $7.42^{\mathrm{bc}}$ & $5.80^{\mathrm{a}}$ & $8.37^{\mathrm{c}}$ & $0.51-0.69$ & 897 & $<0.05$ & $<0.05$ \\
\hline
\end{tabular}

${ }^{1}$ Scale of importance: $0=$ not important; 5 = somewhat important; and $10=$ critically important.

${ }^{2} \mathrm{C}=$ Central (Colorado, Kansas, Montana, Nebraska, North Dakota, South Dakota, and Wyoming); MW = Midwest (Illinois, Indiana, Iowa, Michigan, Minnesota, Missouri, Ohio, and Wisconsin); NE = Northeast (Connecticut, Delaware, Maine, Massachusetts, New Hampshire, New Jersey, New York, Pennsylvania, Rhode Island, and Vermont); NW = Northwest (Idaho, Oregon, and Washington); SE = Southeast (Alabama, Arkansas, Florida, Georgia, Kentucky, Louisiana, Maryland, Mississippi, North Carolina, South Carolina, Tennessee, Virginia, West Virginia); and SW = Southwest (Arizona, California, Nevada, New Mexico, Oklahoma, Texas, and Utah).

${ }^{3}$ Probability of an effect of region $(P<0.05)$; NS $=$ not significant.

${ }^{4}$ Probability of a difference $(P<0.05)$ between western $(\mathrm{C}, \mathrm{NW}$, and $\mathrm{SW})$ and eastern regions $(\mathrm{MW}, \mathrm{NE}$, and $\mathrm{SE})$; NS = not significant.

${ }^{\text {abcd } M e a n s}$ within rows with different superscripts are significantly different $(P<0.05)$.

gest that producers' exposure to litigation, either directly or indirectly, may augment or diminish the relative importance of judicial attitudes as a LDF, as may be the case of producers within the NE and NW regions. In recent history, several highly publicized lawsuits have been filed involving producers in these regions. Furthermore, overall importance of this LDF indicates that producers may actively avoid areas with a history of litigation over waste management issues; however, this conclusion cannot be corroborated by the type of data collected in this study.

Public perception. The public perception of animal agriculture $(7.95 \pm 0.06$; Table 4$)$ was the ninth most important LDF overall. No significant effects of region or herd size were observed, indicating public perception concerns were consistently important across the United States and among all sizes of operations. Whereas this LDF does not directly impact the daily operation of the dairy business, it does impact the emotional well being and community acceptance of the manager and his/her family. These implications suggest that this LDF may impose long-term risks to the business, and producers may actively seek locations with favorable attitudes toward animal agriculture.

Marketing. Factors related to milk marketing and processing were among those LDF determined to be of high importance. The average price of milk ( $8.79 \pm 0.05$; Table 4) was the third most important LDF overall. Relative importance of this LDF differed across regions $(P<0.001$; Table 5). The $\mathrm{C}, \mathrm{SE}$, and $\mathrm{SW}$ regions rated the average mailbox price of milk significantly more important $(9.80 \pm 0.20)$ than did the NE and NW regions $(8.36 \pm 0.30 ; P<0.01)$. There were no differences across herd sizes. An interaction between region and herd size $(P<0.05$; Table 6$)$ occurred in which large herds in the $\mathrm{NE}(7.22 \pm 0.74)$ considered the price of milk to be less important than did large herds in the $\mathrm{C}, \mathrm{MW}, \mathrm{SE}$, and SW regions $(10.6 \pm 0.21 ; P<0.01)$. The perceived importance of milk price tends to be heavily influenced by regional market characteristics that extend beyond the base price of milk. The results suggest that factors including milk premiums or contractual agreements, such as the Northeast Compact, may affect the relative importance of this LDF at the regional level.

Proximity to large fluid milk markets $(8.00 \pm 0.06$; Table 4) was also characterized as being of high relative importance. Importance varied across regions $(P<0.01$; Table 5). The SE region considered proximity to markets to be significantly more important $(9.19 \pm 0.31)$ than did the $\mathrm{C}, \mathrm{NE}, \mathrm{NW}$, and $\mathrm{SW}$ regions $(8.09 \pm 0.14$; $P<0.01)$. Western regions considered this LDF to be significantly less important $(8.01 \pm 0.18)$ than did east- 
Table 6. Least squares mean level of importance of selected location decision factors among herd sizes within regions. ${ }^{1}$

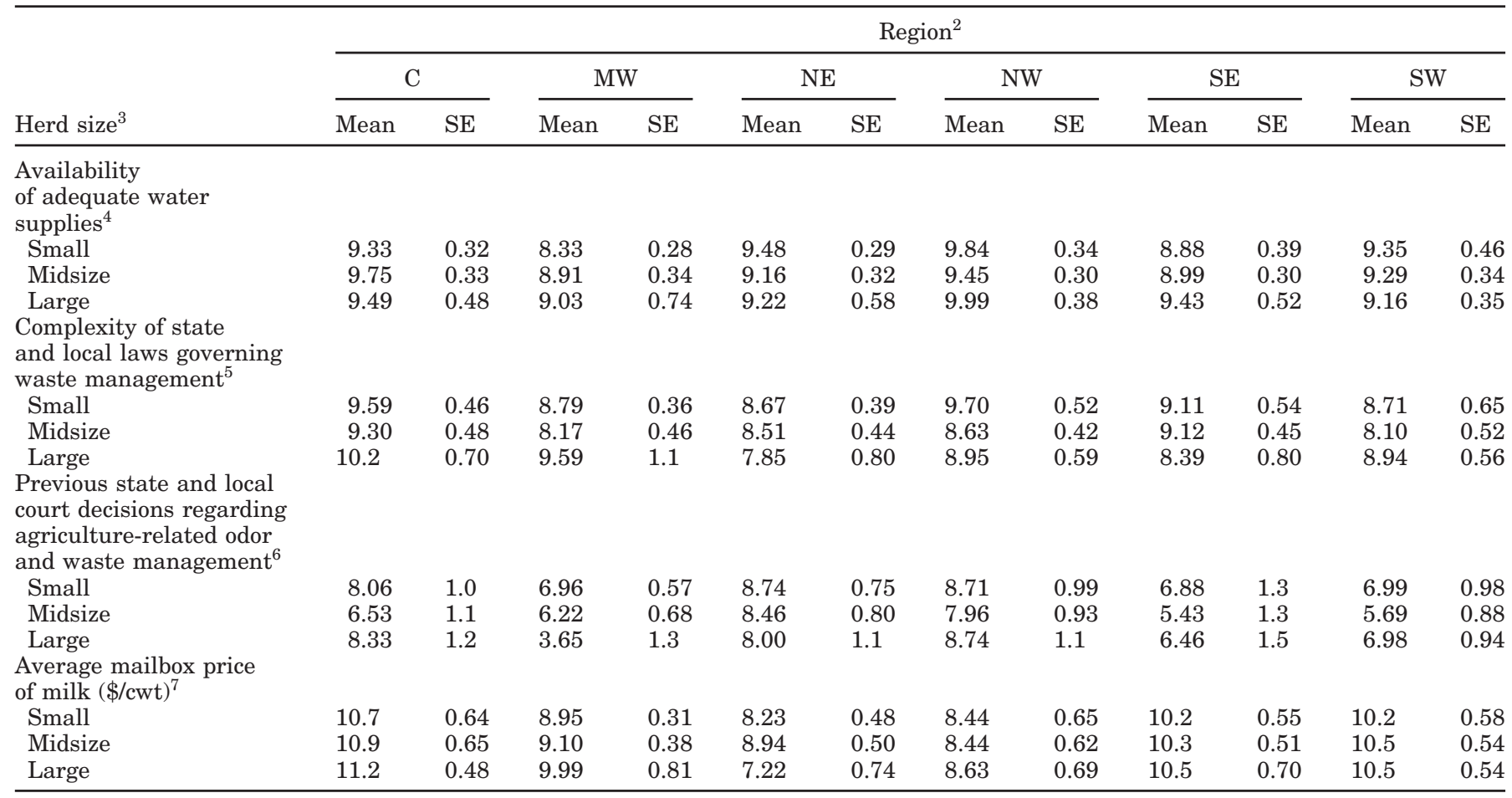

${ }^{1}$ Scale of importance: $0=$ not important; $5=$ somewhat important; and $10=$ critically important.

${ }^{2} \mathrm{C}=$ Central (Colorado, Kansas, Montana, Nebraska, North Dakota, South Dakota, and Wyoming); MW = Midwest (Illinois, Indiana, Iowa, Michigan, Minnesota, Missouri, Ohio, and Wisconsin); NE = Northeast (Connecticut, Delaware, Maine, Massachusetts, New Hampshire, New Jersey, New York, Pennsylvania, Rhode Island, and Vermont); NW = Northwest (Idaho, Oregon, and Washington); SE = Southeast (Alabama, Arkansas, Florida, Georgia, Kentucky, Louisiana, Maryland, Mississippi, North Carolina, South Carolina, Tennessee, Virginia, West Virginia); and SW = Southwest (Arizona, California, Nevada, New Mexico, Oklahoma, Texas, and Utah).

${ }^{3}$ Small $=1$ to 99 milking cows; Midsize $=100$ to 499 milking cows; Large $=>499$ cows.

${ }^{4}$ An interaction occurred in which importance was greater among Large herds within the NW (9.99 \pm 0.38$)$ than among herds of comparable size within all other regions $(9.27 \pm 0.14 ; P<0.01)$.

${ }^{5}$ An interaction occurred in which importance was lesser among Large herds within the NE region $(7.85 \pm 0.80)$ than among herds of similar sizes in all other regions $(9.22 \pm 0.17 ; P<0.10)$.

${ }^{6}$ An interaction occurred in which importance was greater among Large herds within the C, NE, and NW regions (8.36 \pm 0.358$)$ than among herds of similar sizes in all other regions $(5.70 \pm 0.37 ; P<0.01)$.

${ }^{7}$ An interaction occurred in which importance was lesser among large herds in the NE (7.22 \pm 0.74$)$ than among Large herds in the C, $\mathrm{MW}, \mathrm{SE}$, and SW regions $(10.6 \pm 0.21 ; P<0.01)$.

Table 7. Least squares means for importance of location decision factors that differed by herd size.

\begin{tabular}{|c|c|c|c|c|c|c|c|}
\hline & \multicolumn{3}{|c|}{ Herd size ${ }^{2}$} & $\mathrm{SE}$ range & $\mathrm{n}$ & $P^{3}$ & $\begin{array}{l}\text { Larger vs. } \\
\text { smaller } \\
P^{4}\end{array}$ \\
\hline Nutrient load capacity of land & $8.10^{\mathrm{b}}$ & $8.36^{\mathrm{ab}}$ & $8.68^{\mathrm{a}}$ & 0.27 to 0.32 & 905 & $<0.01$ & $<0.05$ \\
\hline Availability of trained labor for unskilled positions (milkers, etc.) & $6.36^{\mathrm{b}}$ & $7.17^{\mathrm{a}}$ & $7.32^{\mathrm{a}}$ & 0.33 to 0.39 & 891 & $<0.001$ & $<0.001$ \\
\hline Local density of dairy farms & $6.00^{\mathrm{a}}$ & $4.98^{\mathrm{b}}$ & $5.10^{\mathrm{ab}}$ & 0.39 to 0.59 & 896 & $<0.05$ & $<0.05$ \\
\hline
\end{tabular}

\footnotetext{
${ }^{1}$ Scale of importance: $0=$ not important; 5 = somewhat important; and $10=$ critically important.

${ }^{2}$ Small $=1$ to 99 milking cows; Midsize $=100$ to 499 milking cows; Large $=>499$ cows.

${ }^{3}$ Probability of an effect of herd size $(P<0.05)$.

${ }^{4}$ Probability of a difference $(P<0.05)$ between smaller herds $(1$ to 99 milking cows $)$ and larger herds $(>99$ milking cows).

${ }^{\text {ab }}$ Means within rows with different superscripts are significantly different $(P<0.05)$.
} 
ern regions $(8.69 \pm 0.19 ; P<0.01)$. Regional differences indicate that the importance of accessibility to large fluid milk markets may be related to perceived milk price benefits, as there is often a negative correlation between distance from large fluid markets and milk price.

With respect to processing, proximity to milk processors and handlers $(7.87 \pm 0.06$; Table 4$)$ was characterized as being of high importance. Importance of this LDF varied across regions $(P<0.01$; Table 5$)$. The NW region characterized the proximity to processors as being significantly more important $(8.88 \pm 0.33)$ than did the MW, NE, and SE regions $(7.72 \pm 0.18 ; P<0.01)$. Furthermore, regions within the western United States considered this LDF to be significantly more important $(8.56 \pm 0.19)$ than did eastern regions $(7.72 \pm 0.18 ; P<$ 0.001 ). Overall importance of this factor may be indicative of the impact proximity to processors can have on profitability since close proximity may minimize product transportation costs. Observed differences among regions may be related to processor accessibility within particular regions and associated benefits.

Cost factors. The costs of hauling milk $(8.26 \pm 0.06$; Table 4$)$ and of feed inputs $(8.13 \pm 0.06)$ were characterized as being highly important and were (respectively) the sixth and seventh most important LDF overall. No differences were observed in importance of either of those cost factors among regions or herd sizes. These LDF were significantly more important $(P<0.01)$ than direct costs associated with utilities (average cost of utilities $=7.29 \pm 0.07$ ) and labor (average local hourly wage $=6.35 \pm 0.07$ ). The overall importance of $\mathrm{LDF}$ associated with costs indicates that producers may place emphasis on maximizing profitability through cost control. The results also suggest that producers may actively seek locations that offer competitive operating costs.

Tax structure and economic incentives. The cost of financing (7.83 \pm 0.07 ; Table 4) and state and local property tax rates $(7.60 \pm 0.06)$ were characterized as being highly important. With respect to tax rates, it is interesting to note that property tax rates $(7.60 \pm 0.06$; Table 4) were significantly more important than income tax rates $(7.40 \pm 0.07 ; P<0.10)$. There is little that can be done from an accounting standpoint to alter property taxes. In contrast, the amount of income taxes to be paid may be manipulated through accounting procedures. Lack of regional differences suggests that locality and applicability of taxes did not influence the overall importance of these factors; however, results may have differed if each state had been evaluated on an individual class.

Among nonagricultural industries, much emphasis is placed on the availability of economic incentives to encourage relocation. Respondents to this study, however, characterized the existence of economic incentives to locate in an area (tax abatements, grants, low interest loans, etc.) as being only moderately important (7.15 \pm 0.08 ; Table 4 ) when relocating their own or an advisee's dairy farm. Relative importance of this LDF differed among regions $(P<0.05$; Table 5$)$. Western regions attached considerably more importance to economic incentives $(7.70 \pm 0.27)$ than did eastern regions $(6.59 \pm$ $0.25 ; P<0.05)$. No differences were found among herd sizes. Many areas of the central and southwestern United States have utilized economic incentives as a means of attracting dairy development. Regional differences indicate that individuals who have previously capitalized on incentives or are members of agricultural communities that offer economic incentives may actively seek locations that offer such incentives.

Labor. The dairy industry has placed much emphasis on labor-related issues. In spite of the popularity of such issues, the availability of skilled labor (7.00 \pm 0.08 ; Table 4) and trained labor for unskilled positions (6.90 \pm 0.08 ) was considered to be of moderate importance to the location decision. No differences in importance of either LDF were observed among regions; however, differences were found among herd sizes. Having adequate pools of skilled labor was more important among midsize and large herds $(7.54 \pm 0.32)$ than among small herds $(6.56 \pm 0.36 ; P<0.0001$; Table 7). A similar trend was found with the availability of trained labor for skilled positions since this LDF was more important among midsize and large herds (7.25 \pm 0.300 ; Table 7) than among small herds $(6.36 \pm 0.33 ; P<0.001)$.

The manner in which herd size affects perceived importance of the availability of these types of labor is likely a direct implication of two generalized characteristics of small and midsize to large-scale dairy production. Smaller dairy farms tend to rely heavily on family and operator labor, whereas larger herds generally hire nonfamily labor. It is reasonable to expect that the need to hire nonfamily labor would increase the importance of labor availability issues. The second characteristic involves the increasing use of new production technologies that require skilled or specially trained labor (computerized milking system and feeding centers, etc.). Larger herds are often first to incorporate such production technologies as a means of increasing efficiency, thus rendering the availability of skilled or trained labor more important among herds of larger scales.

Infrastructure. The importance of dairy service providers, such as veterinarians, milk processors, and milk equipment suppliers, was evaluated based on the number of service providers in an area and proximity to those service providers. Accessibility to service provid- 
ers was consistently more important than the number of service providers within an area. For example, proximity to veterinarians was of high moderate importance $(7.27 \pm 0.07$; Table 4$)$, whereas the number of veterinarians in the local area was of low moderate importance $(5.98 \pm 0.08)$. These results indicate that availability of service providers within close proximity to a producer is of greater value than having a variety of providers from which to choose.

The local density of dairy farms was considered to be of low moderate importance (5.59 \pm 0.07 ; Table 4). No effects of region were observed on importance of this LDF; however, there were differences among herd sizes. Small-herd operators considered this LDF to be significantly more important $(6.00 \pm 0.39)$ than did midsize and large-herd operators $(5.04 \pm 0.35 ; P<0.05$; Table 7). These results suggest that small herds may associate high farm densities with perceived social or businessrelated benefits, such as opportunities for contracting milk prices or obtaining greater access to service providers.

Other LDF. The quality of the state and local (county or parish) Extension program was considered to be of low moderate importance to the location decision (5.47 \pm 0.09 ; Table 4). These results suggest that during the location decision process, the quality of the Extension programs in the area is of little relative importance to the selection of a location. These results cannot be extrapolated to determine the overall value of Extension programming and do not evaluate the role Extension may play in assisting producers with the location decision.

Factors that were among the least important encompass a wide variety of LDF. Many of these LDF reflect community characteristics rather than business-related factors, such as proximity to a shopping mall (4.52 \pm 0.08 ; Table 4$)$ and proximity to recreational areas $(3.24 \pm 0.81)$. These results may indicate that dairy producers seeking to relocate place primary emphasis on business concerns. Reviewed literature, however, indicates that the importance of qualitative concerns, such as community attributes, will increase as the decision process progresses and it becomes necessary to differentiate between two or three final sites (Schmenner, 1982).

Some LDF considered to be of low relative importance pertained to specific production systems utilized by a small number of producers. For example, the presence of established niche markets in the local area (4.14 \pm 0.1 ; Table 4) was the fourth least important LDF overall. It is necessary to recognize that the perceived importance of LDF related to specialized production systems is likely greater among producers engaging in those systems than among producers who do not.

\section{LDF by Region}

Multivariate analyses of all LDF indicated significant differences across regions $(P<0.01)$. Whereas some of the 10 most important LDF were relatively consistent across all regions, some differences in the ranks were observed (Table 8), although the probability of specific differences cannot be assessed.

The supply of locally grown forages was among the 10 most important LDF within the $\mathrm{C}$ region only (Table 8). Importance of this LDF is likely linked to the traditionally high utilization of contract forage production within this area. These results suggest that producers engaged in contract forage production or consumption may place a higher value on local forage supplies since shipping costs would significantly impact feed costs; however, data were not collected that would substantiate this postulate.

Availability of specialized utility services was among the 10 most important LDF within the $\mathrm{C}$ and NW regions only (Table 8). Compared to other regions, with perhaps the exception of the SW, both the $\mathrm{C}$ and $\mathrm{NW}$ regions have growing numbers of large-scale operations likely to require specialized utility services, such as three-phase electricity, thus increasing the importance of such services. Regional characteristics may also influence relative importance of this $\mathrm{LDF}$. The $\mathrm{C}$ region tends to be of lesser population and industrialization than other regions, and farms are likely to be located considerable distances from population centers. Gaining access to specialized utility services in these areas may logistically and economically be a significant challenge, thus increasing the relative importance of this LDF. Within the NW, importance was likely influenced by significant power shortages experienced in this area during the time frame of the study.

Proximity to milk processors and handlers was among the 10 most important LDF within all regions except the MW and SE (Table 8). Both of these regions have a relatively high density of processors and handlers compared with other regions. This suggests that the importance of proximity to processors and handlers is negatively correlated with current accessibility to product intermediaries.

The cost of financing was among the most important LDF within the NE and SE regions only (Table 8). Relative to other regions in the United States, dairy farms within the NE and SE require greater capital investments because of the types of facilities mandated by the climatic conditions of these regions. Therefore, producers within these regions are likely to seek significantly larger loans than are producers within the central and western regions. Furthermore, there tends to be fewer agricultural loaning institutions in the eastern 
Table 8. The 10 most important location decision factors within regions as determined by least squares means.

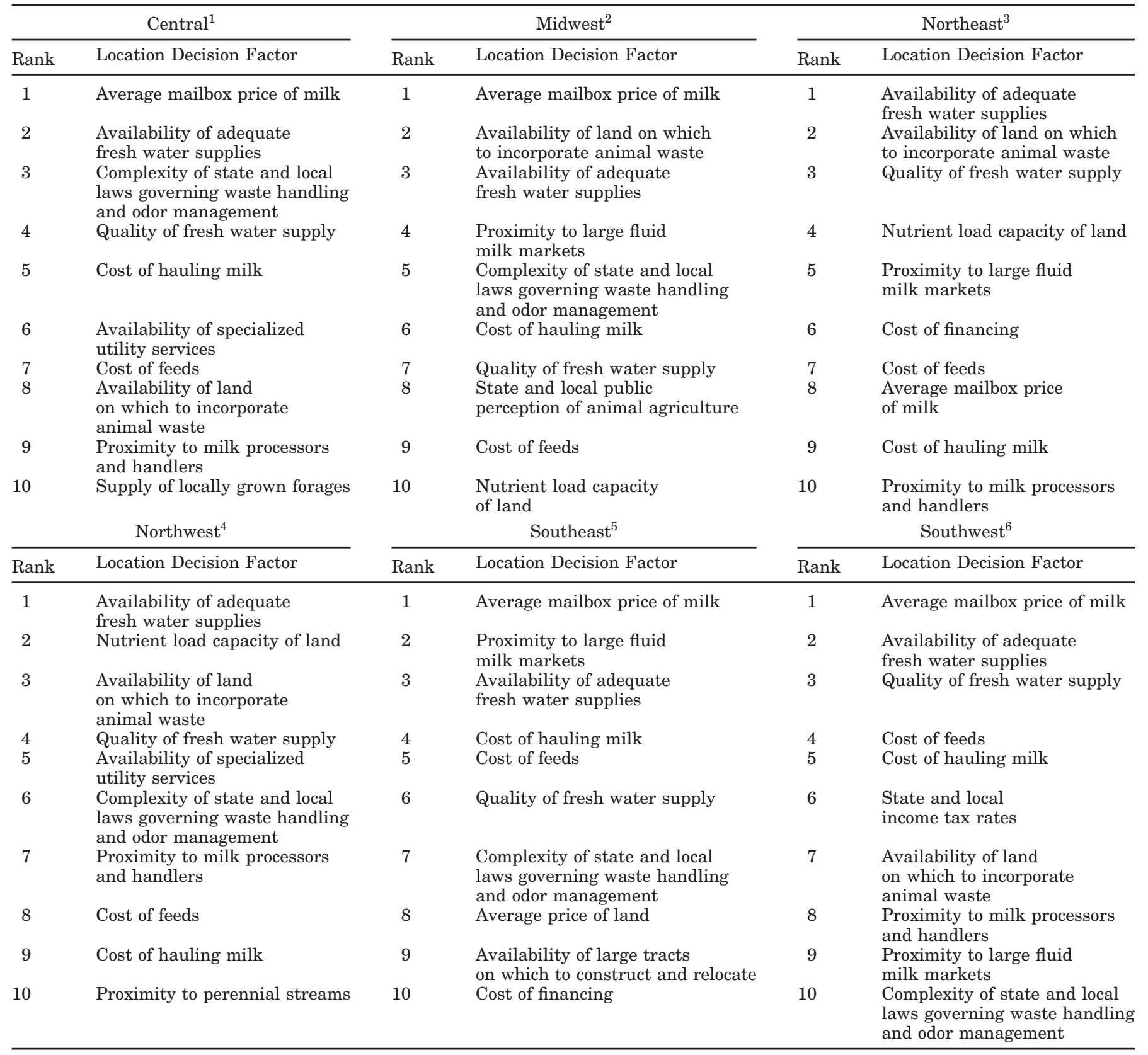

${ }^{1}$ Central = Colorado, Kansas, Montana, Nebraska, North Dakota, South Dakota, and Wyoming.

${ }^{2}$ Midwest = Illinois, Indiana, Iowa, Michigan, Minnesota, Missouri, Ohio, and Wisconsin.

${ }^{3}$ Northeast $=$ Connecticut, Delaware, Maine, Massachusetts, New Hampshire, New Jersey, New York, Pennsylvania, Rhode Island, and Vermont.

${ }^{4}$ Northwest $=$ Idaho, Oregon, and Washington.

${ }^{5}$ Southeast = Alabama, Arkansas, Florida, Georgia, Kentucky, Louisiana, Maryland, Mississippi, North Carolina, South Carolina, Tennessee, Virginia, and West Virginia.

${ }^{6}$ Southwest $=$ Arizona, California, Nevada, New Mexico, Oklahoma, Texas, and Utah.

United States. As a result, producers are likely to face considerable competition from nonagricultural industries for favorable financing rates. Both of these regional characteristics are likely to influence the overall importance of the cost of financing to the location decision.

State and local income tax rates were among the 10 most important LDF within the SW region only (Table 
Table 9. The 10 most important location decision factors within herd sizes as determined by least squares means.

\begin{tabular}{|c|c|c|c|c|c|}
\hline \multicolumn{2}{|r|}{ Small ${ }^{1}$} & \multicolumn{2}{|r|}{ Midsize $^{2}$} & \multicolumn{2}{|r|}{ Large $^{3}$} \\
\hline Rank & Location Decison Factor & Rank & Location Decision Factor & Rank & Location Decision Factor \\
\hline 1 & $\begin{array}{l}\text { Average mailbox price } \\
\text { of milk }\end{array}$ & 1 & $\begin{array}{l}\text { Average mailbox price } \\
\text { of milk }\end{array}$ & 1 & $\begin{array}{l}\text { Average mailbox price } \\
\text { of milk }\end{array}$ \\
\hline 2 & $\begin{array}{l}\text { Availability of adequate } \\
\text { fresh water }\end{array}$ & 2 & $\begin{array}{l}\text { Availability of adequate } \\
\text { fresh water }\end{array}$ & 2 & $\begin{array}{l}\text { Availability of adequate } \\
\text { fresh water }\end{array}$ \\
\hline 3 & $\begin{array}{l}\text { Complexity of state and local } \\
\text { laws governing waste handling } \\
\text { and odor management }\end{array}$ & 3 & $\begin{array}{l}\text { Complexity of state and local } \\
\text { laws governing waste handling } \\
\text { and odor management }\end{array}$ & 3 & $\begin{array}{l}\text { Complexity of state and local } \\
\text { laws governing waste handling } \\
\text { and odor management }\end{array}$ \\
\hline 5 & Cost of feeds & 5 & Cost of hauling milk & 5 & $\begin{array}{l}\text { Availability of land on which } \\
\text { to incorporate animal waste }\end{array}$ \\
\hline 6 & Cost of hauling milk & 6 & Cost of feeds & 6 & Nutrient load capacity of land \\
\hline 7 & $\begin{array}{l}\text { Availability of land on which } \\
\text { to incorporate animal waste }\end{array}$ & 7 & Quality of fresh water supply & 7 & $\begin{array}{l}\text { Proximity to large fluid } \\
\text { milk markets }\end{array}$ \\
\hline 8 & Average cost of utilities & 8 & Nutrient load capacity of land & 8 & Quality of fresh water supply \\
\hline
\end{tabular}

\footnotetext{
${ }^{1}$ Small $=1$ to 99 milking cows.

${ }^{2}$ Midsize $=100$ to 499 milking cows.

${ }^{3}$ Large $=>499$ milking cows .
}

8). Relative to other regions, the dairy industry in the SW has experienced a significantly high growth rate. Much of this growth has occurred through expansion and relocation. For producers who expand, income tax rates become an important consideration since income taxes are applicable to income reinvested in the business. As a result, the portion of income reinvested is no longer available to cover tax expense, and the cash flow of the business is affected. Thus, income tax rates become an important consideration for expanding operations.

Factors relative to the regulatory component of waste management were among the 10 most important LDF within the MW, NE, and NW regions (Table 8). These LDF include the nutrient load capacity of land and proximity to perennial streams. The importance of these LDF may indicate a greater awareness of waste management regulations within these regions relative to other areas of the United States. In the NW, this awareness is likely the product of a traditional emphasis on regulatory compliance, whereas awareness within the MW and NE may be directly related to uncertainty over pending regulatory measures.

\section{LDF by Herd Size}

Multivariate analyses indicated that the overall importance of LDF was affected by herd size $(P<0.05)$. Whereas LDF determined to be among the 10 most important were relatively consistent across herd sizes, some marked differences in the rankings between herd sizes were observed (Table 9), taking into account, how- ever, that the probability of specific differences in the ranks cannot be assessed.

Unlike small or midsize herds, large herds identified proximity to milk processors and handlers as being among the 10 most important LDF (Table 9). Large herds often produce quantities of milk that necessitate daily shipments, thus rendering proximity to processing intermediaries a physical requirement. Furthermore, proximity to processing intermediaries may be financially beneficial since it would reduce transportation costs.

The average cost of construction was among the 10 most important LDF among midsize herds (Table 9). The importance of this LDF may indicate that midsize herds seeking to relocate are highly concerned with initial capital expenditures when compared with smaller and larger herds. It is reasonable to expect, based on these results, that midsize herds intending to relocate often seek to simultaneously expand production activities, thus increasing importance of this LDF.

Unlike midsize and large herds, small herds identified the average cost of utilities as being among the most important LDF (Table 9). The importance of the cost of utilities may be indicative of challenges imposed by economies of scale. Large-scale operations, which are generally large utilities consumers, may have opportunities to contract utility rates comparable to those contracted by nonagricultural industries. In contrast, small operations typically do not require large enough quantities of utilities to afford this opportunity. As a result, the cost of utilities becomes a viable concern for small operations seeking to control costs. 


\section{CONCLUSIONS}

Analyses of LDF revealed that three factors were consistently rated as being the most important to the location decision. Those factors included the availability of water, availability of land on which to incorporate animal waste, and average mailbox price of milk. It is interesting to note that the availability of water and availability of land for waste management purposes are often primary concerns shared by citizens in communities where dairy operations are being located. Factors related to the daily requirements of dairy production activities dominated those LDF determined to be of high importance, thus supporting the hypothesis that LDF determined to be most important would reflect daily production activities of dairy farms. Observed differences in the relative importance of LDF among subclasses of respondents supported the hypothesis that importance would vary among respondents from different regions and with different herd sizes. In particular, region and herd size were determined to have significant effects on overall importance of LDF evaluated.

A review of prior research revealed a significant lack of informational resources available to dairy producers who are seeking to relocate, especially for small herds. It is anticipated that the results of this study will encourage the development of tools that can assist producers in identifying potential sites for relocation. This study also provides useful information for economic development programs desiring to enhance the dairy industry within their localities since results indicate that such agencies may benefit from creating targeted marketing programs based on the demographic subclasses discussed.

The conclusions of this study suggest that future research will be necessary to develop a better understanding of the location decision for relocating dairy farms. Such research may focus exclusively on the population of dairy producers that have relocated or evaluate specific categories of LDF. Future studies may also incorporate anthropological examinations of motivations underlying the relocation of dairy farms.

\section{ACKNOWLEDGMENTS}

The authors would like to extend a sincere note of thanks to all state agencies, professional organizations, industry publications, and industry conference organizers that provided address lists; B Moyer, Vermont Department of Agriculture, Food and Markets, Dairy Section; P. Spike's Spring 2000 Animal Science 647 course; all industry professionals and dairy producers that re- sponded to the study; and Venture Milling Company, a division of Purdue Farms Inc., for financial support.

\section{REFERENCES}

Abdalla, C. W., L. E. Lanyon, and M. C. Hallberg. 1995. What we know about historical trends in firm location decisions and regional shifts: Policy issues for an industrializing animal sector. Am. J. Agric. Econ. 77:1229-1236.

Barrett, E. E. 1998. Determining factors affecting the location of large scale dairy operations in Ohio. M.S. Thesis, The Ohio State Univ., Columbus.

Berk, R. A. 1983. Applications of the general linear model to survey data. Pages 495-546 in Handbook of Survey Research. P. H. Rossi, J. D. Wright, and A. B. Anderson, ed. Academic Press Inc., New York, NY.

Browning, J. E. 1980. How to Select a Business Site: The Executive's Location Guide. 1st ed. McGraw-Hill Co., New York, NY.

Butler, L. J., and J. Ekboir. 1997. Appropriate market is key to dairying in Imperial Valley. Feedstuffs 69:16-29.

Chapman, K., and D. F. Walker. 1991. Industrial Location: Principles and Policies. 2nd ed. Basil Blackwell Inc., Cambridge, MA.

Cohen Mason, J. 1996. Corporate relocations: On the move. Manag. Rev. 85:33-37.

Dairy Herd Management Staff. 2000. Critical points for relocation. Dairy Herd Manag. 37:22-23.

Dillman, D. A. 2000. Mail and Internet Surveys: The Tailored Design Method. 2nd ed. John Wiley and Sons Inc., New York, NY.

Eby, L. T., and J. E. A. Russell. 2000. Predictors of employee willingness to relocate for the firm. J. Voc. Behav. 57:42-61.

Gould, S., and L. E. Penley. 1985. A study of the correlates of the willingness to relocate. Acad. Manag. J. 28:472-478.

Hack, G. D. 1999. Site Selection for Growing Companies. 1st ed. Quorum Books, Westport, CT.

Harvey, W. R. 1982. Least-squares analysis of discrete data. J. Anim. Sci. 54:1067-1071.

Karakaya, F., and C. Canel. 1998. Underlying dimensions of business location decisions. Indust. Manag. Data Syst. 98:321-329.

Lohr, S. L. 1999. Sampling: Design and Analysis. 1st ed. Duxbury Press, Albany, NY.

McPherson, E. M. 1995. Plant Location Selection Techniques. 1st ed. Noyes Publication, Park Ridge, NJ.

Miller, L. E., and K. L. Smith. 1983. Handling nonresponse issues. J. Ext. 21:45-50.

Mooney, R. 2000. The best place to dairy. Dairy Today 16:8-11.

Oppenheim, A. N. 1992. Questionnaire Design, Interviewing, and Attitude Measurement. 2nd ed. St. Martin's Press, New York, NY.

Schmenner, R. W. 1982. Making Business Location Decisions. 1st ed. Prentice-Hall, Inc., Englewood Cliffs, NJ.

Smith, J. F., J. P. Harner III, M. L. Brouk, D. V. Armstrong, M. J. Gamroth, M. J. Meyer, G. Boomer, G. Bethard, and D. Putnam. 1999. Many issues involved in dairy expansion, relocation. Feedstuffs 71(28):11-22.

Stroh, L. K. 1999. Does relocation still benefit corporations and employees? An overview of the literature. Human Res. Manag. Rev. 9:279-308.

Sullivan, J., U. Vasavada, and M. Smith. 2000. Environmental regulation \& location of hog production. Pages 19-23 in Agric. Outlook. USDA Econ. Res. Serv., Washington, DC. 274:19-23. Online. Available: http://usda.mannlib.cornell.edu/reports/erssor/economics/ao-bb/2000/ao274.pdf. Accessed June 20, 2001.

NASS. 1997. Census of Agriculture. National Agricultural Statistics Service Online. Available: http://www.usda.gov/nass. Accessed November 7, 2000.

NASS. 2001. Ag Statistics Database. National Agricultural Statistics Service. Online. Available: http://www.usda.gov/nass. Accessed September 18, 2001. 